\title{
GCU
}

Glasgow Caledonian

University

University for the Common Good

\section{On-line monitoring of relative dielectric losses in cross-bonded cables using sheath currents}

Yang, Yang; Hepburn, D.M.; Zhou, Chengke; Wenjun, Zhou; Bao, Yuchuan

Published in:

IEEE Transactions on Dielectrics and Electrical Insulation

DOI:

10.1109/TDEI.2017.005438

Publication date:

2017

Document Version

Author accepted manuscript

Link to publication in ResearchOnline

Citation for published version (Harvard):

Yang, Y, Hepburn, DM, Zhou, C, Wenjun, Z \& Bao, Y 2017, 'On-line monitoring of relative dielectric losses in cross-bonded cables using sheath currents', IEEE Transactions on Dielectrics and Electrical Insulation, vol. 24, no. 5, pp. 2677-2685. https://doi.org/10.1109/TDEI.2017.005438

\section{General rights}

Copyright and moral rights for the publications made accessible in the public portal are retained by the authors and/or other copyright owners and it is a condition of accessing publications that users recognise and abide by the legal requirements associated with these rights.

Take down policy

If you believe that this document breaches copyright please view our takedown policy at https://edshare.gcu.ac.uk/id/eprint/5179 for details

of how to contact us. 


\title{
On-line Monitoring of Relative Dielectric Losses in Cross- bonded Cables using Sheath Currents
}

\author{
Yang Yang, D. M. Hepburn, Chengke Zhou \\ Glasgow Caledonian University \\ School of Engineering and Built Environment \\ Glasgow, G4 0BA, UK \\ Wenjun Zhou \\ Wuhan University \\ School of Electrical Engineering \\ Wuhan, 430072, China \\ and Yuchuan Bao \\ China State Grid \\ Wuhan Power Supply Company \\ Wuhan, 430022, China
}

\begin{abstract}
Cross-bonded three-phase single-core Cross-linked Polyethylene (XLPE) cables are widely used in power transmission and distribution systems. A great deal has been published on on-line monitoring of $\mathrm{HV}$ cable systems to prevent failure. Relative Dielectric Losses (DL) monitoring reveals the general condition of the cable insulation. Generally, DL measurement relies on measuring operating voltage and insulation leakage current. The main challenge to on-line monitoring of DL in Cross-bonded High voltage (CB HV) cables is the interconnectedness of metal sheath. Measured sheath currents are a combination of the leakage currents of each section and the imbalanced circulating current. Differentiating the leakage current of each interconnected section from the measured data is complex. The second challenge is that co-axial cables are used to connect cable sheaths to cable link boxes, for ease of installation and protection against moisture. As a result, any measured value contains currents from the two sheaths connecting at a joint. The third challenge is that it is hard to obtain the reference voltage synchronously and with high accuracy. Consequently, this paper investigates separation of leakage current components and analysis of DL based on leakage currents without reference voltage. A circuit model is proposed to describe the leakage current separation method for CB HV cables to allow on-line monitoring of DL, and the criterion required for assessing relative change of DL among different phases or sections of the cable for insulation deterioration are presented. Operational measurements from a cable system are analyzed and discussed. Results show that there is no significant deterioration in this monitored major section of a CB HV cable system.
\end{abstract}

Index Terms - Cable insulation, leakage currents, AC measurements, dielectric losses, XLPE insulation.

\section{INTRODUCTION}

Cross-bonded high voltage (CB HV) cable systems are widely adopted for long-distance power transmission and distribution in urban networks [1]. Typical cross-bonded cable systems are implemented in major sections: each major section has 9 cross-bonded minor sections [2]. In comparison with single-end-grounded cable systems or both-end-grounded

Manuscript received on 3June 2016, in final form 20 March 2017, accepted 21 June 2017.

Corresponding author: Chengke Zhou: C.Zhou@gcu.ac.uk. cable systems, a cross-bonded cable system is grounded at both ends of the major section with cross-bonding, or interconnection, of the minor cable section sheaths of the three phases to reduce or eliminate the effect of the induced voltage in the sheath and to reduce the sheath circulating currents [3].

However, the interconnection of the sheath creates differences between the on-line insulation monitoring methods used in short-distance and long-distance power cables [5]. Conventional off-line measurements utilize bridge methods to 
calculate the dielectric loss (DL) factor [4] or phase difference between operational voltage vector and leakage current vector to compute DL factor. However, these methods have several drawbacks and cannot be applied in on-line monitoring. Firstly, under cross-bonded sheath connection, sheath currents are a combination of leakage currents from different minor sections and unbalanced circulating currents [6]. The unbalanced circulating currents result from the differences in section lengths, unbalanced laying and unbalanced load currents [8]. Consequently, it is hard to detect the pure leakage current for the calculation of DL angle. Secondly, for ease of installation and to avoid moisture intrusion, co-axial link cables are used for connecting the sheaths from joints to link boxes [7]. But this results in the current sensor clamped on the co-axial link cables detecting the vector sum of two sheath currents. In addition, for safety and operational reasons, it is usually difficult to detect the operational voltage directly at the terminals or joints. Finally, the phase of voltage signals from the potential transformer (PT) in substations is not the same as that of voltages at the terminals or joints [9], and it is hard to quantify the difference.

Bing Pang and et al. in [21], proposed an on-line DL factor monitoring method to determine the faults in minor sections of a major cross-bonded cable section. The method required acquisition of voltage signals and, as mentioned above, it is difficult to obtain these when the cable circuit is in operation.

Marzinotto et al. in [22], proposed on-line measurement of the sheath-to-ground current to detect cable sheath faults. Although this offers the possibility of detecting sheath faults in a cross-bonded cable system, it cannot reflect the insulation condition.

Consequently, a new method to address these issues is proposed in this paper, i.e. by measuring the current at the coaxial cables to determine the relative dielectric loss. In the cross-bonded major section, as shown in Figure 1, 12 clamptype current sensors are installed at the co-axial link cables. The proposed Leakage Current Separation Method (LCSM) aims to distinguish the leakage currents from the sheath currents based on the 12 detected currents. The purpose of relative DL among three phases, based on the results of LCSM, is to determine the relative insulation condition in different cable sections without acquiring the operational voltage signals.

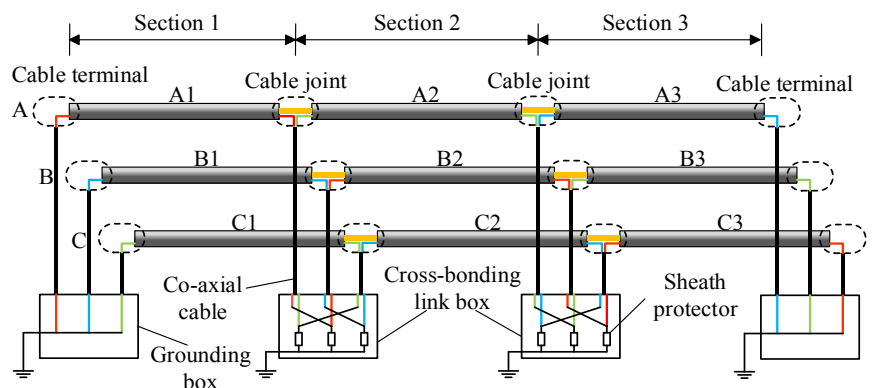

Figure 1. Major section of CB cable system.

\section{THEORETICAL BACKGROUND}

\subsection{EQUIVALENT CIRCUIT OF INSULATED CABLE}

XLPE insulated cables, behaving as transmission lines to transmit current signals, can be considered as the equivalent circuit shown in Figure 2 [8]. The equivalent impedance of the conductor is $Z_{c}$; the equivalent resistance of the XLPE insulation is $R_{i}$; the equivalent capacitance of the XLPE insulation is $C_{i}$; and the equivalent impedance of the metal sheath is $Z_{m L}$ and $Z_{m R}$. Because the equivalent impedance of XLPE insulation is much greater than the equivalent impedance of semi-conductors, the semiconductor layers are ignored in this model. As such, XLPE insulated cable has the equivalent network shown in Figure 2.

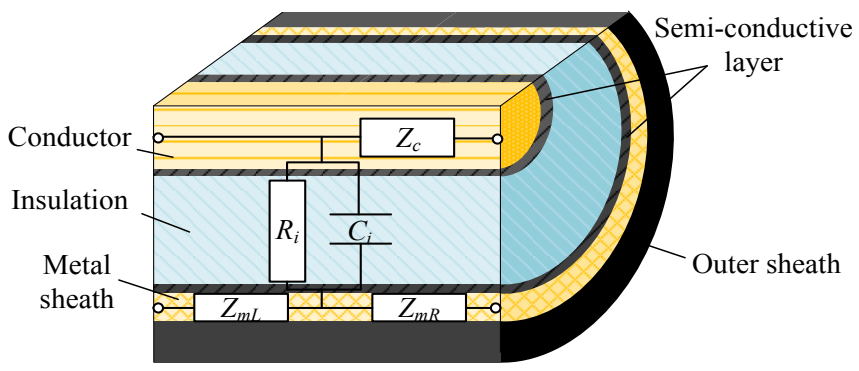

Figure 2. Equivalent circuit of XLPE insulated cable.

\subsection{LEAKAGE CURRENT}

Based on the equivalent circuit established in section 2.1, the AC leakage current, $I_{l}$, flowing through the insulation into the metal sheath, divides into two currents. The currents, $I_{L}$ and $I_{R}$, flow in different directions to the earth, as presented in Figure 3.

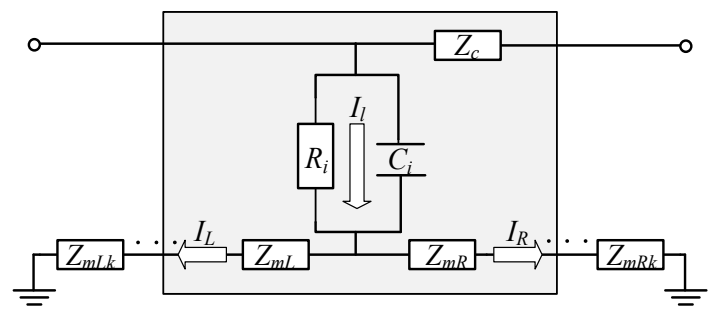

Figure 3. Leakage current flowing pattern in XLPE insulated cable.

Considering the interconnection of different minor sections, $\Sigma \boldsymbol{Z}_{m L}$ is the sum of equivalent impedances of minor sections left to ground, while $\Sigma \boldsymbol{Z}_{m R}$ is the sum of equivalent impedances of minor sections right to ground.

$$
\begin{aligned}
& \sum \boldsymbol{Z}_{m L}=\boldsymbol{Z}_{m L}+\ldots+\boldsymbol{Z}_{m L k} \\
& \sum \boldsymbol{Z}_{m R}=\boldsymbol{Z}_{m R}+\ldots+\boldsymbol{Z}_{m R k}
\end{aligned}
$$

The leakage current will flow in both directions in the sheath. The proportion of the currents flowing in the two directions depends on the impedances $\Sigma \boldsymbol{Z}_{m L}$ and $\Sigma \boldsymbol{Z}_{m R}$. It is difficult to determine the proportion of each current, presented in equations (3) and (4), but the relationship is always established as indicated in equation (5).

$$
\boldsymbol{I}_{L}=\frac{\sum \boldsymbol{Z}_{m R}}{\sum \boldsymbol{Z}_{m L}+\sum \boldsymbol{Z}_{m R}} \times \boldsymbol{I}_{l}
$$




$$
\begin{gathered}
\boldsymbol{I}_{R}=\frac{\sum \boldsymbol{Z}_{m L}}{\sum \boldsymbol{Z}_{m L}+\sum \boldsymbol{Z}_{m R}} \times \boldsymbol{I}_{\boldsymbol{l}} \\
\boldsymbol{I}_{\boldsymbol{l}}=\boldsymbol{I}_{\boldsymbol{L}}+\boldsymbol{I}_{\boldsymbol{R}}
\end{gathered}
$$

\subsection{LEAKAGE CURRENT SEPARATION METHOD}

Based on the major section of the CB HV cable system shown in Figure 1 and the division rule of the leakage currents under the equivalent circuit of an XLPE insulated cable, the leakage current separation method was proposed. Figure 4 presents the installation of current sensors and superimposed current components in sheath loops.

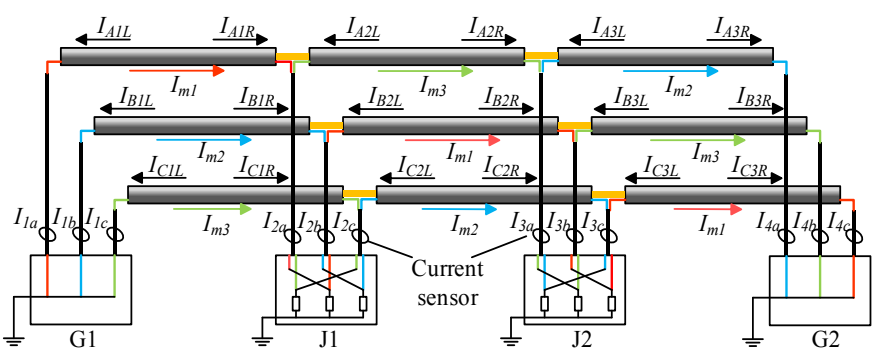

Figure 4. The superimposed currents and the measurement installation

As indicated in Figure 4, $\boldsymbol{I}_{A n L}, \boldsymbol{I}_{A n R}, \boldsymbol{I}_{B n L}, \boldsymbol{I}_{B n \boldsymbol{R}}, \boldsymbol{I}_{C n L}$ and $\boldsymbol{I}_{C n \boldsymbol{R}}$ $(\mathrm{n}=1 \ldots 3)$ are the left-to-ground leakage currents and right-toground leakage currents of the XLPE insulated cable respectively. $\boldsymbol{I}_{\boldsymbol{m} \boldsymbol{I}}$ is the imbalance circulating current in loop 1 (A1, B2 and C3). $\boldsymbol{I}_{\boldsymbol{m} 2}$ is the imbalance circulating current in loop 2 (B1, C2 and A3). $\boldsymbol{I}_{\boldsymbol{m} 3}$ is the imbalance circulating current in loop 3 (C1, A2 and B3). $\boldsymbol{I}_{1 a}, \boldsymbol{I}_{1 b}$ and $\boldsymbol{I}_{1 c}$ are the measured currents at three ports of grounding box G1. $\boldsymbol{I}_{2 a}, \boldsymbol{I}_{2 b}$ and $\boldsymbol{I}_{2 c}$ are the measured currents at three ports of link box J1. $\boldsymbol{I}_{3 a}, \boldsymbol{I}_{3 b}$ and $\boldsymbol{I}_{3 c}$ are the measured currents at three ports of link box J2. $\boldsymbol{I}_{4 c}, \boldsymbol{I}_{4 b}$ and $\boldsymbol{I}_{4 c}$ are the measured currents at three ports of grounding box $\mathrm{G} 2$.

\subsection{MEASURED CURRENTS AT LINK BOXES DIRECTLY GROUNDED}

If the direction from load side to source side is specified as the positive direction in Figure 4, the currents detected by the current sensors installed at the ports of grounding boxes on both sides, G1 and G2, can be shown as an example using a single loop from Figure 4. Cable sections A1, B2 and C3 form the loop indicated in Figure 5.

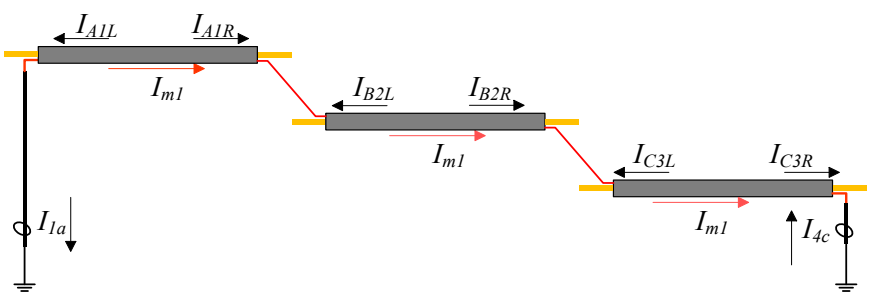

Figure 5. Example: current sensors at grounding boxes in sheath loop 1.

When considering the currents detected at the point of $\boldsymbol{I}_{\boldsymbol{I a}}$ and $\boldsymbol{I}_{4 c}$, the equations can be deduced as indicated in equation (6).

$$
\left\{\begin{array}{l}
\boldsymbol{I}_{1 a}=+\boldsymbol{I}_{A 1 L}+\boldsymbol{I}_{B 2 L}+\boldsymbol{I}_{C 3 L}-\boldsymbol{I}_{m 1} \\
\boldsymbol{I}_{4 c}=-\boldsymbol{I}_{A 1 R}-\boldsymbol{I}_{B 2 R}-\boldsymbol{I}_{C 3 R}-\boldsymbol{I}_{m 1}
\end{array}\right.
$$

The signals at measuring points, $\boldsymbol{I}_{1 a}$ and $\boldsymbol{I}_{4 c}$, are the results of the superimposition of the current vectors from the description provided after Figure 4. This inference is also suitable for the currents measured at the grounding boxes of the other two loops. The results are shown as Equations (7) and (8).

$$
\begin{array}{r}
\left\{\begin{array}{l}
\boldsymbol{I}_{1 b}=+\boldsymbol{I}_{B 1 L}+\boldsymbol{I}_{C 2 L}+\boldsymbol{I}_{A 3 L}-\boldsymbol{I}_{m 2} \\
\boldsymbol{I}_{4 a}=-\boldsymbol{I}_{B 1 R}-\boldsymbol{I}_{C 2 R}-\boldsymbol{I}_{A 3 R}-\boldsymbol{I}_{m 2}
\end{array}\right. \\
\left\{\begin{array}{l}
\boldsymbol{I}_{1 c}=+\boldsymbol{I}_{C 1 L}+\boldsymbol{I}_{A 2 L}+\boldsymbol{I}_{B 3 L}-\boldsymbol{I}_{\boldsymbol{m} 3} \\
\boldsymbol{I}_{4 b}=-\boldsymbol{I}_{C 1 R}-\boldsymbol{I}_{A 2 R}-\boldsymbol{I}_{B 3 R}-\boldsymbol{I}_{m 3}
\end{array}\right.
\end{array}
$$

\subsection{MEASURED CURRENTS AT LINK BOXES WHERE PROTECTIVE EARTHING IS APPLIED}

As co-axial cables are widely used in three-port link boxes, it is important to make clear what the current sensors will detect at the measuring points at link boxes $\mathrm{J} 1$ and $\mathrm{J} 2$.

In the co-axial cables used to connect the minor section sheaths between the cable joints and link boxes, there will be two sheath currents flowing. One minor section sheath current will flow through the co-axial cable's central conductor and the other will flow through the sheath, as indicated in Figure 6.

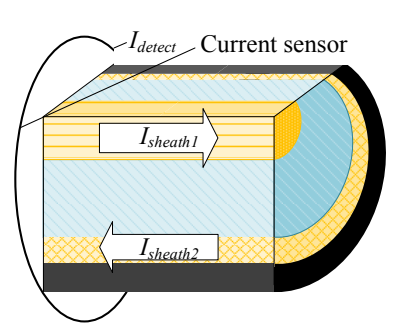

(a)

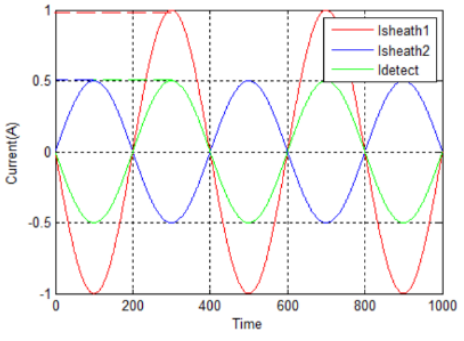

(b)
Figure 6. (a) Two minor section sheath currents flowing in core and sheath of the co-axial cable. (b) Separation of currents detected by current sensor

Figure 6a presents the cross section of the co-axial cable showing the two sheath currents flowing through the co-axial cable. Figure $6 \mathrm{~b}$ presents the detected signal, and the two sheath currents, when applying the current sensor at the coaxial cable. The current detected by the sensor is the vector sum of the two currents, as demonstrated in equation (9).

Based on Ampere's circuit theory, assuming the direction of $\boldsymbol{I}_{\text {sheath } 1}$ is the positive reference direction, $\boldsymbol{I}_{\text {detect }}$ is the superimposed vector of $\boldsymbol{I}_{\text {sheath } 1}$ and $\boldsymbol{I}_{\text {sheath } 2}$, as shown in equation (9).

$$
\boldsymbol{I}_{\text {detect }}=\boldsymbol{I}_{\text {sheath } 1}-\boldsymbol{I}_{\text {sheat } 2}
$$

Developing equation (9), and taking the measuring point $I_{2 a}$ as an example to explore the combination of sheath currents at link boxes, equations (10) to (12) are developed based on the simplified circuit in Figure 7.

Current, $\boldsymbol{I}_{2 a}$, is the combination of $\boldsymbol{I}_{2 a m \boldsymbol{I}}$ (the sheath current of loop 1 at measuring point $I_{2 a}$ ) and $\boldsymbol{I}_{2 a m 3}$ (the sheath current of loop 3 at measuring point $I_{2 a}$ ). As $\boldsymbol{I}_{2 a m 3}$ is in the opposite direction to $\boldsymbol{I}_{2 a m 1}$ at the measuring point, the vector 


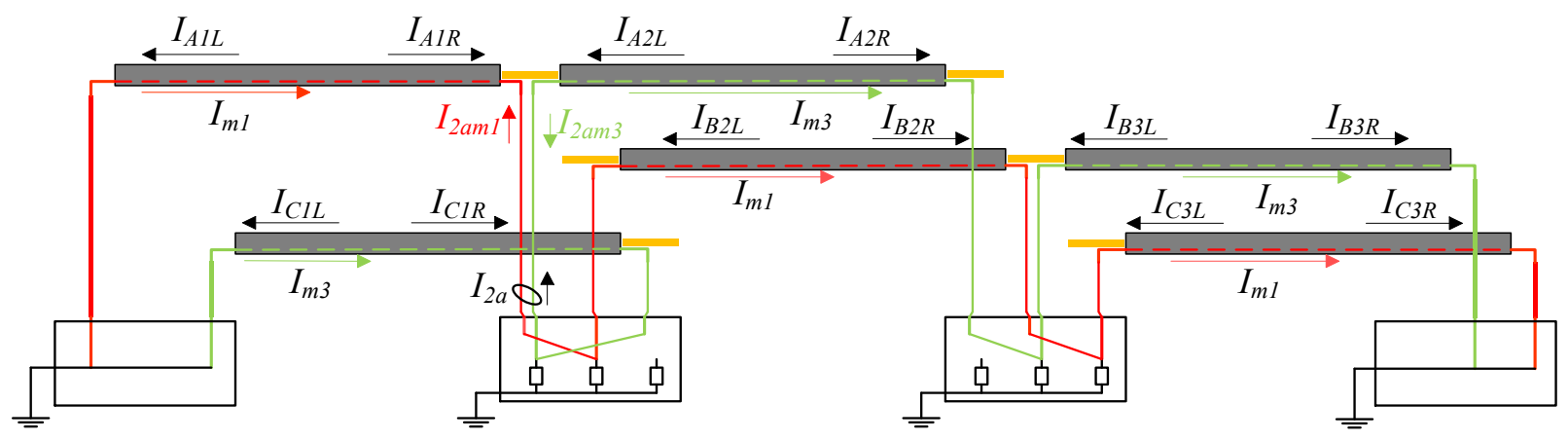

Figure 7. Example: measured currents, $I_{2 a}$, at link box on the left side.

relationships can be presented as equations (10) to (12).

$$
\begin{gathered}
\boldsymbol{I}_{2 a m 1}=-\boldsymbol{I}_{A 1 R}+\boldsymbol{I}_{B 2 L}+\boldsymbol{I}_{C 3 L}-\boldsymbol{I}_{m 1} \\
\boldsymbol{I}_{2 a m 3}=-\boldsymbol{I}_{C 1 R}+\boldsymbol{I}_{A 2 L}+\boldsymbol{I}_{B 3 L}-\boldsymbol{I}_{\boldsymbol{m} 3} \\
\boldsymbol{I}_{2 a}=\boldsymbol{I}_{2 a m 1}-\boldsymbol{I}_{2 a m 3}
\end{gathered}
$$

This set of equations can be generalized to the other five current sensors at link boxes in Figure 4, namely $\boldsymbol{I}_{2 b}, \boldsymbol{I}_{2 c}, \boldsymbol{I}_{3 a}$, $\boldsymbol{I}_{3 b}$ and $\boldsymbol{I}_{3 c}$. The results are listed as Equation (13) below.

$$
\left\{\begin{array}{l}
\boldsymbol{I}_{3 b}=-\boldsymbol{I}_{A 1 R}-\boldsymbol{I}_{B 2 R}+\boldsymbol{I}_{C 3 L}-\boldsymbol{I}_{m 1}+\boldsymbol{I}_{C 1 R}+\boldsymbol{I}_{A 2 R}-\boldsymbol{I}_{B 3 L}+\boldsymbol{I}_{m 3} \\
\boldsymbol{I}_{2 b}=-\boldsymbol{I}_{B 1 R}+\boldsymbol{I}_{C 2 L}+\boldsymbol{I}_{A 3 L}-\boldsymbol{I}_{m 2}+\boldsymbol{I}_{A 1 R}-\boldsymbol{I}_{B 2 L}-\boldsymbol{I}_{C 3 L}+\boldsymbol{I}_{m 1} \\
\boldsymbol{I}_{3 c}=-\boldsymbol{I}_{B 1 R}-\boldsymbol{I}_{C 2 R}+\boldsymbol{I}_{A 3 L}-\boldsymbol{I}_{m 2}+\boldsymbol{I}_{A 1 R}+\boldsymbol{I}_{B 2 R}-\boldsymbol{I}_{C 3 L}+\boldsymbol{I}_{m 1} \\
\boldsymbol{I}_{2 c}=-\boldsymbol{I}_{C 1 R}+\boldsymbol{I}_{A 2 L}+\boldsymbol{I}_{B 3 L}-\boldsymbol{I}_{m 3}+\boldsymbol{I}_{B 1 R}-\boldsymbol{I}_{C 2 L}-\boldsymbol{I}_{A 3 L}+\boldsymbol{I}_{m 2} \\
\boldsymbol{I}_{3 a}=-\boldsymbol{I}_{C 1 R}-\boldsymbol{I}_{A 2 R}+\boldsymbol{I}_{B 3 L}-\boldsymbol{I}_{m 3}+\boldsymbol{I}_{B 1 R}+\boldsymbol{I}_{C 2 R}-\boldsymbol{I}_{A 3 L}+\boldsymbol{I}_{m 2}
\end{array}\right.
$$

\subsection{LEAKAGE CURRENTS SEPARATION RESULTS}

In equations (6), (7), (8), (12) and (13), each current sensor output was the summation of leakage currents and unbalanced circulating currents. However, the leakage current of each cable section is still unknown. Consequently, in [10], a leakage currents separation method was proposed to solve this complex current superimposition. This was established under the premise that all these current signals are detected at the same time and these signals are all vectors rather than purely numeric values [11].

This method aims to separate the leakage current from each cable insulation $\left(A_{n}, B_{n}\right.$ and $\left.C_{n}, \mathrm{n}=1 \ldots 3\right)$. The relationships of the detected cable current waveforms $\left(\boldsymbol{I}_{\boldsymbol{m} \boldsymbol{a}}, \boldsymbol{I}_{\boldsymbol{m} \boldsymbol{b}}\right.$ and $\boldsymbol{I}_{\boldsymbol{m} \boldsymbol{c}}, \mathrm{m}=1,2$, $3,4)$ can be presented by the equations listed in Table 1 .

Table 1. The Relationship of Leakage Current Presented by the Detected Currents.

\begin{tabular}{ccc}
\hline $\begin{array}{c}\text { Deduced } \\
\text { currents }\end{array}$ & $\begin{array}{c}\text { The relationship between } \\
\text { leakage currents }\end{array}$ & $\begin{array}{c}\text { The detected currents by } \\
\text { current sensors }\end{array}$ \\
\hline $\boldsymbol{I}_{1 B A}$ & $\boldsymbol{I}_{B 1}-\boldsymbol{I}_{A 1}$ & $\boldsymbol{I}_{1 b}-\boldsymbol{I}_{2 b}-\boldsymbol{I}_{1 a}$ \\
$\boldsymbol{I}_{1 C B}$ & $\boldsymbol{I}_{C 1}-\boldsymbol{I}_{B 1}$ & $\boldsymbol{I}_{1 c}-\boldsymbol{I}_{2 c}-\boldsymbol{I}_{1 b}$ \\
$\boldsymbol{I}_{1 A C}$ & $\boldsymbol{I}_{A 1}-\boldsymbol{I}_{C 1}$ & $\boldsymbol{I}_{1 a}-\boldsymbol{I}_{2 a}-\boldsymbol{I}_{1 b}$ \\
$\boldsymbol{I}_{2 B A}$ & $\boldsymbol{I}_{B 2}-\boldsymbol{I}_{A 2}$ & $\boldsymbol{I}_{2 a}-\boldsymbol{I}_{3 b}$ \\
$\boldsymbol{I}_{2 C B}$ & $\boldsymbol{I}_{C 2}-\boldsymbol{I}_{B 2}$ & $\boldsymbol{I}_{2 b}-\boldsymbol{I}_{3 c}$ \\
$\boldsymbol{I}_{2 A C}$ & $\boldsymbol{I}_{A 2}-\boldsymbol{I}_{C 2}$ & $\boldsymbol{I}_{2 c}-\boldsymbol{I}_{3 a}$ \\
$\boldsymbol{I}_{3 B A}$ & $\boldsymbol{I}_{B 3}-\boldsymbol{I}_{A 3}$ & $\boldsymbol{I}_{3 a}-\boldsymbol{I}_{4 b}+\boldsymbol{I}_{4 a}$ \\
$\boldsymbol{I}_{3 C B}$ & $\boldsymbol{I}_{C 3}-\boldsymbol{I}_{B 3}$ & $\boldsymbol{I}_{3 b}-\boldsymbol{I}_{4 c}+\boldsymbol{I}_{4 b}$ \\
$\boldsymbol{I}_{3 A C}$ & $\boldsymbol{I}_{A 3}-\boldsymbol{I}_{C 3}$ & $\boldsymbol{I}_{3 c}-\boldsymbol{I}_{4 a}+\boldsymbol{I}_{4 c}$ \\
\hline
\end{tabular}

\subsection{RELATIVE CHANGE OF DL ANGLE BASED ON THE LEAKAGE CURRENT RELATIONSHIP}

In operational power transmission systems it is hard to get reference voltage information for the power cable directly. Although the operational voltage could be measured in substations, there is an unknown phase difference from the voltage in the underground cable system. Consideration must also be given to the requirement for a high level of accuracy in the synchronization between voltage transformers and current sensors. This must reach microsecond accuracy as DL of XLPE HV cables is extremely small under normal circumstances.

In situations where measuring the reference voltage vector is not possible, this would interfere with the accuracy for calculating the DL. It is noted in [13] that there can be $\pm 2 \%$ fluctuation in rated voltage under imbalanced load, etc. Any fluctuation of supply voltage would strongly influence the results of the relative tendency of DL.

To overcome the challenges outlined above, an alternative method for determining relative DL, based on leakage currents, is proposed.

\subsection{TRADITIONAL CALCULATION OF DL ANGLE}

As stated in [15], the traditional method to calculate DL angle is based on the measurement of phase difference between leakage current and operating voltage by zerocrossing method, harmonic analysis or fast Fourier transform.

Equation (14) is the formula to calculate DL angle by the phase difference between leakage current and operational voltage, as shown in Figure 8a.

$$
\delta=\frac{\pi}{2}-\left(\theta_{I}-\theta_{U}\right)
$$

Equation (15) is the formula developed under the traditional method, taking into consideration different interference effects [16]: where $\delta_{m}$ is measured DL angle; $\theta_{U m}$ is measured voltage angle; $\theta_{I m}$ is measured leakage current angle; $\gamma_{e}$ is environmental interference; $\delta_{0}, \theta_{U 0}$ and $\theta_{I 0}$ are actual values; $\gamma_{I}$ and $\gamma_{U}$ are intrinsic angle errors of current sensors and voltage transformers. So there will be inevitable measurement error as a result of hardware effects and interference from environment. 


$$
\begin{aligned}
\delta_{m} & =\pi / 2-\left(\theta_{I m}-\theta_{U m}\right)+\gamma_{e} \\
& =\pi / 2-\left(\theta_{I 0}+\gamma_{I}\right)+\left(\theta_{U 0}+\gamma_{U}\right)+\gamma_{e} \\
& =\left(\pi / 2-\left(\theta_{I 0}-\theta_{U 0}\right)\right)+\left(\gamma_{U}-\gamma_{I}+\gamma_{e}\right) \\
& =\delta_{0}+\left(\gamma_{U}-\gamma_{I}+\gamma_{e}\right)
\end{aligned}
$$

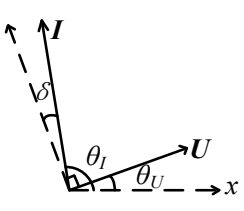

(a)

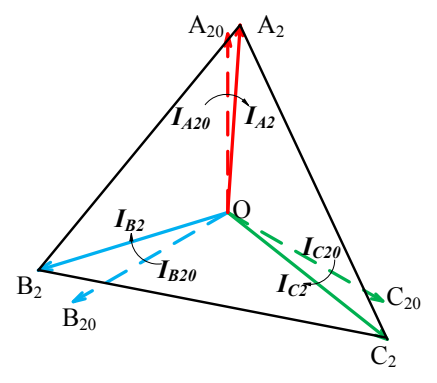

(b)
Figure 8. (a) Traditional phase difference of leakage current and operating voltage; (b) Relative tendency of DL through comparison of three-phase leakage currents.

\subsection{RELATIVE CHANGE OF DL THROUGH COMPARISON OF THREE-PHASE LEAKAGE CURRENTS}

Using the cables $A 2, B 2$ and $C 2$ in section 2 as an examplar, the conclusion can be generalized across the $\mathrm{CB}$ cable system.

Figure $8 \mathrm{~b}$ is used to show the development of the variance in the leakage current vectors for cable insulation in the three segments in section 2, namely $\mathrm{A} 2, \mathrm{~B} 2$ and $\mathrm{C} 2 . \mathrm{OA}_{20}, \mathrm{OB}_{20}$ and $\mathrm{OC}_{20}$ are the vectors of the leakage currents $\left(\boldsymbol{I}_{\boldsymbol{A 2 0} \boldsymbol{0}}, \boldsymbol{I}_{\boldsymbol{B 2 0}}\right.$ and $\left.\boldsymbol{I}_{\boldsymbol{C 2 0} \boldsymbol{\theta}}\right)$ respectively at the initial stage. $\mathrm{OA}_{2}, \mathrm{OB}_{2}$ and $\mathrm{OC}_{2}$ are the vectors of the leakage currents $\left(\boldsymbol{I}_{A 2}, \boldsymbol{I}_{B 2}\right.$ and $\left.\boldsymbol{I}_{C 2}\right)$ after different aging effects. As a result of insulation deterioration happening in all three phases, $\boldsymbol{I}_{\boldsymbol{A 2} \boldsymbol{0}}$ changes to $\boldsymbol{I}_{\boldsymbol{A} 2} ; \boldsymbol{I}_{\boldsymbol{B} \boldsymbol{2} \boldsymbol{\theta}}$ changes to $\boldsymbol{I}_{\boldsymbol{B} \boldsymbol{2}}$ and $I_{C 20}$ changes to $\boldsymbol{I}_{\boldsymbol{C} 2}$.

Based on the fact that the three cables are in the same environment, are constructed of the same material and operate under a consistent voltage, it is possible to judge the relative change in DL from the difference of vectors.

$$
\begin{aligned}
\Delta \delta_{B A m} & =\delta_{B m}-\delta_{A m} \\
& =\left(\delta_{B 0}+\Delta \delta_{B}+\gamma_{B}\right)-\left(\delta_{A 0}+\Delta \delta_{A}+\gamma_{A}\right) \\
& =\left(\delta_{B 0}-\delta_{A 0}\right)+\left(\gamma_{B}-\gamma_{A}\right)+\left(\Delta \delta_{B}-\Delta \delta_{A}\right) \\
& =\Delta \delta_{B}-\Delta \delta_{A}
\end{aligned}
$$

Equation (16) uses the difference between Phase A and Phase $\mathrm{B}$ as an example to demonstrate how this method achieves the measurement of DL angle using leakage current vectors without reference voltage vectors.

Where, $\Delta \delta_{B A m}$ is the difference of DL between Phase A and B. As the cables are of the same length and of the insulation material it can be assumed that the value of $\delta_{B 0}$ is equal to $\delta_{A 0}$. As the cables are in same environmental condition it can also be assumed that the environmental effects on the cables will be the same, therefore, $\gamma_{B}$ is also equal to $\gamma_{A}$. From this, the measured value $\Delta \delta_{B A m}$ will indicate the relative change in DL between Phase A and B with no hardware and environment interference [17].

Table 2 compares the phase A and phase $\mathrm{B}$ and gives the criteria and judgment of relative aging between phases.
Table 2. Judgment of the Relationship of Variation Value of DL Angle between Phases.

\begin{tabular}{cc}
\hline $\begin{array}{c}\text { The relationship of variation value } \\
\text { of DL angle between phases }\end{array}$ & $\begin{array}{c}\text { The judgment of relative aging } \\
\text { between phases }\end{array}$ \\
\hline$\Delta \delta_{B}-\Delta \delta_{A}>0$ & B aged faster than A \\
$\Delta \delta_{B}-\Delta \delta_{A}=0$ & B aged at the same degree of A \\
$\Delta \delta_{B}-\Delta \delta_{A}<0$ & A aged faster than B \\
\hline
\end{tabular}

This method takes into account the impact of the environmental interference and the intrinsic angular error of current sensors without measuring the voltage.

\subsection{THE PROPOSED DL MONITORING METHOD}

Due to the co-axial cables entering the link boxes having a mixture of sheath currents detected by the current sensors, the leakage current separation method above calculates the vector difference of two leakage current vectors instead of a single leakage current vector.

As such, the relationship between the vector difference and relative DL angle needs to be established to determine the aging degree of the XLPE insulation.

As shown in equation (17) $\tan \delta$ has positive correlation with $1 / R(G)$ and $C$ : where $\omega$ is the system angular frequency, which is a consistent for each measurement, and, as indicated in Figure 3, $R$ is the resistance of the cable insulation and $C$ is the capacitance of the cable.

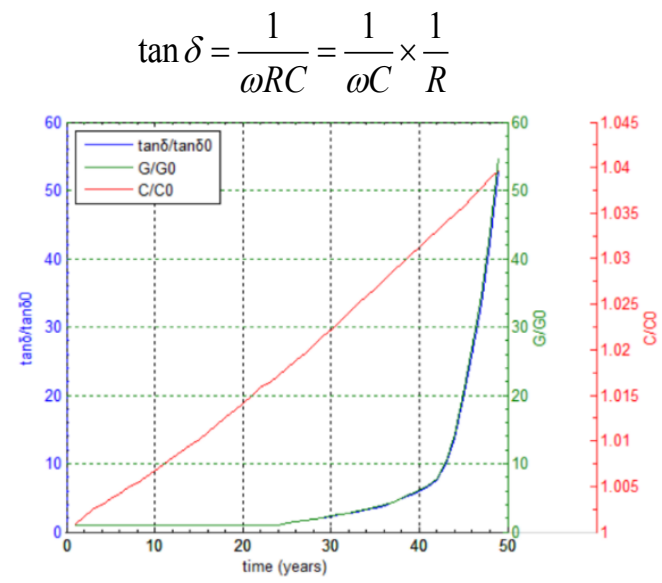

Figure 9. Result of accelerated aging tests [17, 18].

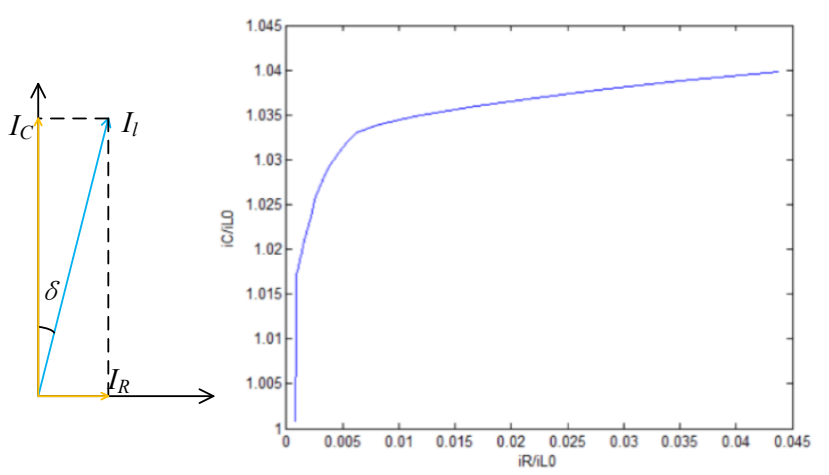

(a)

(b)

Figure 10. (a) Orthogonal decomposition of leakage current, (b) Variation in leakage current component relationships. 
In order to describe the relative degree of aging between phases by the vector difference relationships in Table 1, the relationship between phase difference and vector difference should be known.

Based on [17] and [18], Figure 9 shows the variation of tan $\delta, 1 / R(G)$ and $C$ as insulation ages. As shown in Figure 10a, leakage current can be resolved into resistive, $I_{R}$, and capacitive, $I_{C}$, components. Based on [19], the relationship between $I_{C}$ and $I_{R}$ can be deduced over the life of XLPE cable insulation, as shown in Figure 10b.

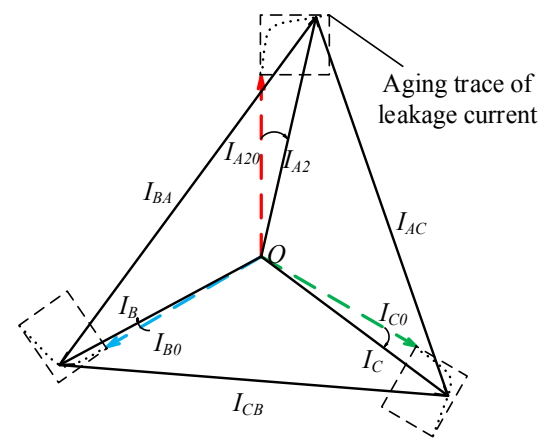

Figure 11. The relationship between the lengths of the deduced current based on the relationship established on the angle difference and aging degree.

As indicated in Figure 11, the track of the development of ageing in the current vector can be assessed. Based on the trace of the leakage current vectors, the angle difference relationships, which were listed in Table 2, can be transferred to the length relationships of vector difference, as listed in Table 3.

Table 3. The Judgment and Criterion of Relative Aging Speed under the Comparison of Three-phase Leakage Currents.

\begin{tabular}{ccc}
\hline Judgment & Judgment based on the length & Relative aging speed \\
\hline$\Delta \delta_{C} \leq \Delta \delta_{B} \leq \Delta \delta_{A}$ & $I_{B A} \geq I_{C B} \geq I_{A C}$ & A2 is fastest \\
$\Delta \delta_{B} \leq \Delta \delta_{C} \leq \Delta \delta_{A}$ & $I_{C B} \geq I_{A C} \geq I_{B A}$ & \\
$\Delta \delta_{C} \leq \Delta \delta_{A} \leq \Delta \delta_{B}$ & $I_{A C} \geq I_{B A} \geq I_{C B}$ & B2 is fastest \\
$\Delta \delta_{A} \leq \Delta \delta_{C} \leq \Delta \delta_{B}$ & & C2 is fastest \\
$\Delta \delta_{B} \leq \Delta \delta_{A} \leq \Delta \delta_{C}$ & $I_{A C} \geq I_{C B} \geq I_{B A}$ & A2 is lowest \\
$\Delta \delta_{A} \leq \Delta \delta_{B} \leq \Delta \delta_{C}$ & $I_{B A} \geq I_{A C} \geq I_{C B}$ & B2 is lowest \\
$\Delta \delta_{A} \leq \Delta \delta_{B} \leq \Delta \delta_{C}$ & & \\
$\Delta \delta_{A} \leq \Delta \delta_{C} \leq \Delta \delta_{B}$ & $I_{C B} \geq I_{B A} \geq I_{A C}$ & C2 is lowest \\
$\Delta \delta_{B} \leq \Delta \delta_{A} \leq \Delta \delta_{C}$ & & \\
$\Delta \delta_{B} \leq \Delta \delta_{C} \leq \Delta \delta_{A}$ & & \\
$\Delta \delta_{C} \leq \Delta \delta_{B} \leq \Delta \delta_{A}$ & &
\end{tabular}

Table 3 illustrates the relationship between relative aging degree and vector of deduced current and the judgment based on the relative DL angle between phases for the whole crossbonded cable system.

The model system was simulated in MATLAB through different aging scenarios for the range of cable sections and results show good consistency.

The whole process can be implemented as an on-line monitoring method for assessing the relative change of DL, i.e. one based on the detected currents measured by the current sensors installed at the ports of link boxes.

\section{Practical implementation AND INITIAL RESULTS}

The on-line monitoring system that this model has been based on is operational in a $110 \mathrm{kV}$ XLPE power cable line in China. The dimensions of the minor sections of the cable arrangement, originally shown as Figure 1, are outlined for the major cable section in Figure 12 below.

As in the original model, there are 12 current sensors applied in the major section. These are installed at the leads of each link and grounding box. The parameters of the system deployed in the tunnel are listed in Table 4.

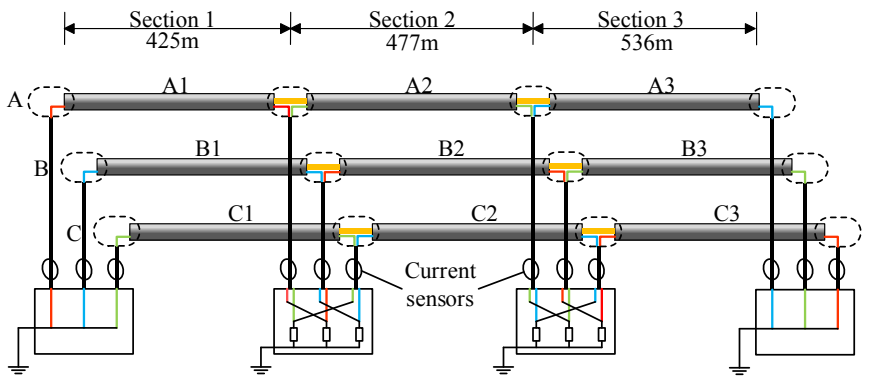

Figure 12. The major section of an $110 \mathrm{kV}$ XLPE CB cable system in China.

Table 4. The Parameters of the Major Section.

\begin{tabular}{c|c}
\hline Thickness of cable insulation & $16 \times 10^{-3} \mathrm{~m}$ \\
Distance between phase A and B & $0.27 \mathrm{~m}$ \\
Distance between phase B and C & $0.27 \mathrm{~m}$ \\
Distance between phase A and C & $0.54 \mathrm{~m}$ \\
Frequency of the voltage & $50 \mathrm{~Hz}$ \\
Working voltage & $110 \mathrm{kV}$ \\
Earth resistance & $4 \Omega$ \\
Maximum AC resistance of conductor at $90{ }^{\circ} \mathrm{C}$ & $0.0232 \Omega / \mathrm{km}$ \\
Maximum AC resistance of sheath at $20{ }^{\circ} \mathrm{C}$ & $0.0426 \Omega / \mathrm{km}$ \\
Tan $\delta$ (Conductor temperature: $95{ }^{\circ} \mathrm{C} \sim 100{ }^{\circ} \mathrm{C}$ ) & $8 \times 10^{-4}$ \\
Cable capacitance & $0.226 \mu \mathrm{F}$ \\
\hline
\end{tabular}

\subsection{RAW DATA FROM CABLE TUNNEL}

Figure 13 shows the raw data from current sensors installed at the ports of the link boxes, $I_{2 a}, I_{2 b}, I_{2 c}, I_{3 a}, I_{3 b}$ and $I_{3 c}$. Figure $13 \mathrm{a}$ is the data collected on 15th December 2014 and Figure $13 \mathrm{~b}$ is the data collected on 26th March 2015. 

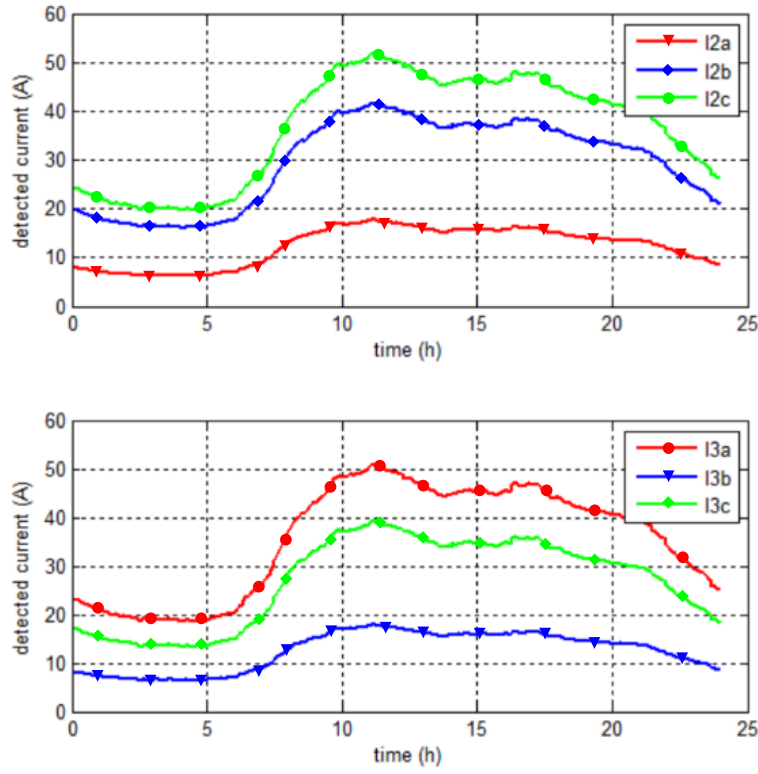

(a) RMS raw data for 15th December 2014
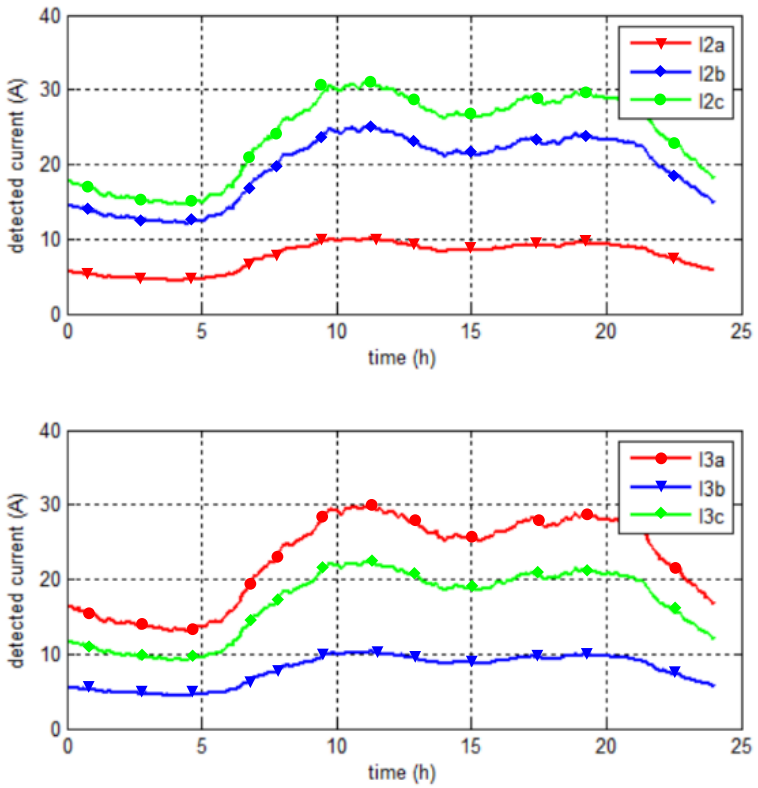

(b) RMS raw data for 26th March 2015

Figure 13. RMS raw data in December 2014 and March 2015.

It should first be noted that the length of each sub-section in this major section is different, sections 1,2 and 3 having lengths of 425,477 and $536 \mathrm{~m}$ respectively, and the load currents of three phases are imbalanced. The result is the existence of circulating currents.

Secondly, the imbalance in the load currents of three phases and the difference in cable lengths among sections will lead to imbalanced currents being detected through different current sensors.

Thirdly, because of the daily fluctuation of load currents, there were big variances in detected currents over the course of a day.

Moreover, due to the seasonal fluctuation of load currents (winter in December and spring in March for this location), the ranges of the detected currents varies considerably, as shown by comparing Figures $13 a$ and $13 b$.

Although the daily raw data curve characteristics are similar, the influence of the season on load current can be seen: the ratio of detected current magnitude of each sensor in different months is about 5:3.

\subsection{THE INFLUENCE OF THE FLUCTUATION OF SYSTEM VOLTAGE}

Figure 14 presents the RMS values of the leakage current separation results. As mentioned before, leakage currents would be influenced by variation of the operating voltage. As the operational voltage is much higher than the voltage in the sheath and the equivalent impedance of the XLPE insulation is much bigger than the equivalent impedance of semi-conductor layers, the equation for determining leakage current can be simplified to equation (18).

$$
I_{\text {leakage }}=\frac{U_{\text {operation }}-U_{\text {sheath }}}{Z_{\text {insulation }}+Z_{\text {other }}} \approx \frac{U_{\text {operation }}}{Z_{\text {insulation }}}
$$

Equation (18) indicates that the variation of operational voltage has an effect on leakage current. Based on regulation GB 12326-2008, the National Standard in China which is in accordance with IEC standard, the system voltage fluctuation is prescribed to be less than $2 \%$ of the rated voltage in an $110 \mathrm{kV}$ transmission line. Consequently, as presented in Figure 14 , the prescribed range of fluctuation in detected currents was from $0.98-1.02$ of the mean value during the detecting period. However, the fluctuation of operational voltage will still strongly influence the leakage currents at the early stage of deterioration. So, to offset the influence of the fluctuation of voltage, the average daily value was used to describe the relative aging.

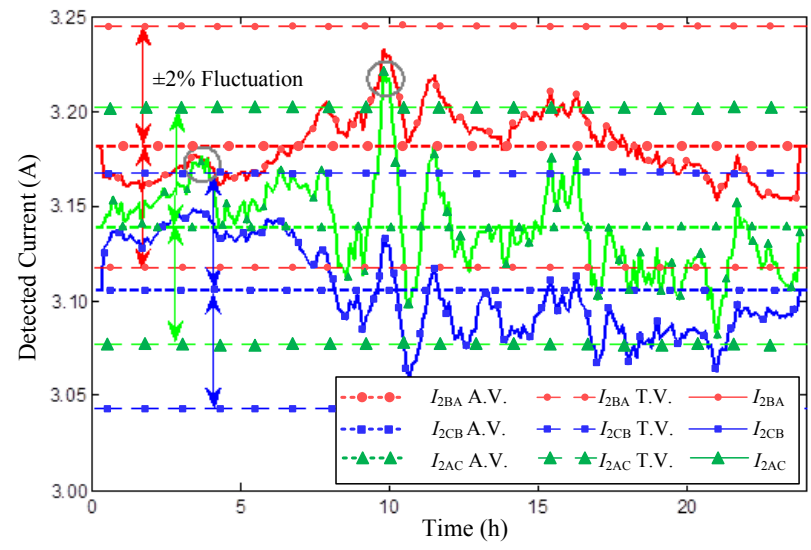

(a) Calculated current RMS values for 15th December 2014 


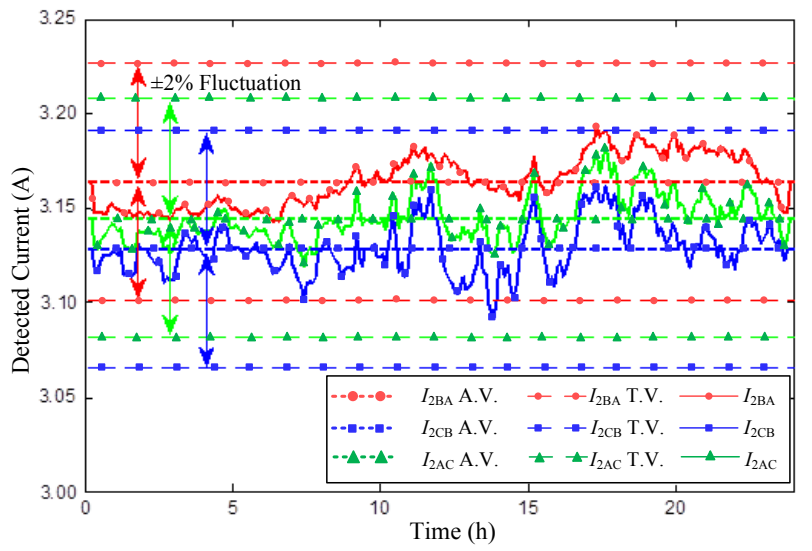

(b) Calculated current RMS values for 26th March 2015

Figure 14. Calculated RMS values of $\boldsymbol{I}_{2 B A}, \boldsymbol{I}_{2 C B}$ and $\boldsymbol{I}_{2 A C}$ for example days. (Note: A.V. is the average value in one day time; T.V. is the threshold value in considering $2 \%$ fluctuation of operating voltage.)

\subsection{ANALYSIS AND SUMMARY 3.3.1 COMPARISON OF VARIATION BETWEEN PHASES}

For the periods analyzed Figure 14 illustrates that relationship (19) holds for the majority of the time on both dates.

$$
I_{2 B A}>I_{2 A C}>I_{2 C B}
$$

The exceptions to the rule are, in Figure 14a, around 10:00 on December $15^{\text {th }}$ there was a sudden increase in $I_{2 A C}$ and, in Figure 14b, around 09:00 in March $26^{\text {th }}$, there was a sudden increase in $I_{2 C B}$.

As it is unlikely that the DL in a cable section would change at the rate indicated in these exceptions, the mean value of each deduced current can be applied to describe the relationship of relative aging degree among three phases to offset the influence of periodical fluctuation. The results of analysis, based on criteria in Table 3, are listed in Table 5.

Table 5. Comparison of analysis among three phases.

\begin{tabular}{ccc}
\hline Data collected & December & March \\
\hline$I_{2 B A}$ & $3.17950 \mathrm{~A}$ & $3.16895 \mathrm{~A}$ \\
$I_{2 C B}$ & $3.10245 \mathrm{~A}$ & $3.13020 \mathrm{~A}$ \\
$I_{2 A C}$ & $3.13925 \mathrm{~A}$ & $3.14825 \mathrm{~A}$ \\
$\begin{array}{c}\text { Relationship between } \\
\text { the valid values } \\
\text { among three phases }\end{array}$ & $I_{2 B A}>I_{2 A C}>I_{2 C B}$ & $I_{2 B A}>I_{2 A C}>I_{2 C B}$ \\
Relative aging degree & The aging degree of & The aging degree of \\
& A2 is the lowest & A2 is the lowest \\
\hline
\end{tabular}

\subsubsection{THE COMPARISON OF VALID VALUE AT DIFFERENT TIME}

When comparing the deduced current at different times, the results are as indicated in Table 6.

Table 6. Comparison of Analysis at Different Example Time.

\begin{tabular}{cccc}
\hline Data collected & December & March & $\begin{array}{c}\text { Percentage } \\
\text { change }\end{array}$ \\
\hline$I_{2 B A}$ & $3.17950 \mathrm{~A}$ & $3.16895 \mathrm{~A}$ & $-0.33 \%$ \\
$I_{2 C B}$ & $3.10245 \mathrm{~A}$ & $3.13020 \mathrm{~A}$ & $+0.89 \%$ \\
$I_{2 A C}$ & $3.13925 \mathrm{~A}$ & $3.14825 \mathrm{~A}$ & $+0.29 \%$ \\
\hline
\end{tabular}

As presented in Figure 13, the average magnitude of raw data in December is much bigger than that in March. As mentioned before, load currents will affect the imbalance circulating currents, i.e. the greater the load current, the greater the circulating current. From this it can be deduced that the load current of all three phases is higher in December than in March. As the tunnel temperature does not change much, the insulation temperature is mainly influenced by load current.

Based on the results in Table 6 there was no significant deterioration in the four month period. However, as insulation degradation processes occur over long periods, c.f. the 30 year design life, a long-term observation strategy is needed.

\section{Conclusion}

In an operational cross-bonded HV cable system, on-line monitoring of relative tendency of DL among phases is established using power-frequency current sensors at link boxes and grounding boxes.

The developed method, which has never been proposed before, achieved the separation of leakage currents in a crossbonded system with three-port link boxes. The method makes on-line monitoring of relative DL possible.

The analysis indicates that there is no significant deterioration of the cable sections under study. However, as the cables are at the start of their operational life, continued monitoring will be carried out to ensure cables remain suitable for use.

In future work, after long-term observation, information on the response of the on-line monitoring system to the effects of seasonal and annual load variation will aim to prove the value of the system in life assessment of HV cable.

\section{REFERENCES}

[1] B. Sheng, W. Zhou, J. Yu, S. Meng, C. Zhou and D. M. Hepburn, "Online PD detection and localization in cross-bonded HV cable system", IEEE Trans. Dielectr. Electr. Insul., Vol. 21, pp. 2217-2224, 2014.

[2] X. Dong, Y. Yuan, Z. Gao, C. Zhou, B. Sheng and H. Zhao, "Analysis of cable failure modes and cable joint failure detection via sheath circulating current”, IEEE Electr. Insul. Conf. (EIC), pp. 294-298, 2014.

[3] R. Jiang, "Aging mechanisms and monitoring of XLPE insulated power cable" in XLPE Power Cable Lines, $2^{\text {nd }}$ ed. Beijing, China, China Electric Power Press, 2009.

[4] H. Zhang, 110-220kV XLPE Cable Insulation On-line Monitoring Technique, Ph.D. dissertation, Wuhan University, SEE, Wuhan, China, 2009.

[5] B. Sheng, C. Zhou, D. M. Hepburn, X. Dong, W. Zhou and J. Yu, "Partial discharge pulse propagation in power cable and partial discharge monitoring system", IEEE Trans. Dielectr. Electr. Insul., Vol. 21, pp. 948-956, 2014.

[6] IEEE Guide for Bonding Shields and Sheaths of Single-Conductor Power Cables Rated $5 \mathrm{kV}$ through $500 \mathrm{kV}$," in IEEE Std 575-2014 (Revision of IEEE Std 575-1988), vol., no., pp.1-83, Sept. 182014.

[7] Chengke Zhou, Wenjun Zhou, D. M. Hepburn, Bojie Sheng, Xiang Dong, and B. Alkali, "PD detection and localisation in cross-bonded HV cable systems," in 22nd International Conference and Exhibition on Electricity Distribution (CIRED 2013), 2013, vol. 5, pp. 0129-0129.

[8] P. Fa-dong et al., "The Design of Distributed On-line Monitoring System for Metal Sheath's Circulating Current of Cross-linked Power Cables," 2008 International Conference on High Voltage Engineering and Application, Chongqing, 2008, pp. 562-565.

[9] B. Sheng, C. Zhou, D. M. Hepburn, X. Dong, W. Zhou and J. Yu, "Investigation of partial discharge propagation in cross-bonded HV cable systems," 2014 IEEE Electrical Insulation Conference (EIC), Philadelphia, PA, 2014, pp. 19-23. 
[10] Y. Yang, D. M. Hepburn, C. Zhou, W. Jiang, B. Yang, and W. Zhou, "On-line Monitoring and Trending Analysis of Dielectric Losses in Cross- bonded High Voltage Cable Systems," Jicable 2015, pp. 1-6, 2015.

[11] Y. Yang, D. M. Hepburn, C. Zhou, W. Jiang, B. Yang and W. Zhou, "On-line monitoring and trending of dielectric loss in a cross-bonded HV cable system," 2015 IEEE 11th International Conference on the Properties and Applications of Dielectric Materials (ICPADM), Sydney, NSW, 2015, pp. 301-304.

[12] IEC 60038-2009, IEC standard voltages, IEC, 2009.

[13] Z. Li, X. Chu, X. Zeng and N. Chen, "A New On-line Measurement System of Dielectric Loss Angle for High Voltage Capacitive Apparatus," 2007 IEEE Industry Applications Annual Meeting, New Orleans, LA, 2007, pp. 1512-1516.

[14] M. Wang, F. C. Lu and H. M. Li, "Analytical processing of online monitored dissipation factor based on morphological filter," in IEEE Transactions on Dielectrics and Electrical Insulation, vol. 11, no. 5, pp. 840-846, Oct. 2004.

[15] IEC 60287-1-1, Electric cables - Calculation of the current rating - Part 1-1: Current rating equations (100\% load factor) and calculation of losses - General, IEC, 2006.

[16] X. Huang, R. Liao, X. Hu, H. Bai and Z. Yan, "Application of the synthetic relative measuring method in on-line monitoring of dielectric loss factor", High voltage electrical appliances, vol.6, pp 1-3, 2001.

[17] H. Wang, S. Cheng, X. Wen and Y. Chen, "AC Insulation Characteristic of XLPE in the Course of Aging", High Voltage Engineering. vol. 31, no. 3, pp. 7-9, 2005.

[18] H. X. Wang, Y. L. Wang and A. Z. Han, "Insulation Parameters Characteristics of XLPE Cable in the course of Its Aging within CuSO4 Electrolyte," 2008 International Conference on High Voltage Engineering and Application, Chongqing, 2008, pp. 331-334.

[19] J. C. Fothergill, S. J. Dodd, L. A. Dissado, T. Liu and U. H. Nilsson, "The measurement of very low conductivity and dielectric loss in XLPE cables: a possible method to detect degradation due to thermal aging," in IEEE Transactions on Dielectrics and Electrical Insulation, vol. 18, no. 5, pp. 1544-1553, October 2011.

[20] B. Pang, B. Zhu, X. Wei, S. Wang and R. Li, "On-line monitoring method for long distance power cable insulation," in IEEE Transactions on Dielectrics and Electrical Insulation, vol. 23, no. 1, pp. 70-76, February 2016.

[21] M. Marzinotto and G. Mazzanti, "The Feasibility of Cable Sheath Fault Detection by Monitoring Sheath-to-Ground Currents at the Ends of Cross-Bonding Sections," in IEEE Transactions on Industry Applications, vol. 51, no. 6, pp. 5376-5384, Nov.-Dec. 2015.

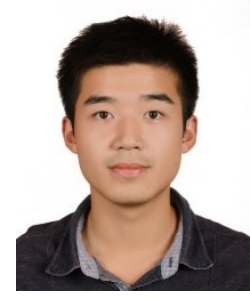

Yang Yang (M'15) was born in Hubei, China in 1991. He received the B.Sc. degree from Wuhan University of Technology in 2013 and M.Sc. degree from Wuhan University in 2016. Now he is a Ph.D. student in Glasgow Caledonian University, who is mainly research on the development of the measurement of insulation condition, including dielectric loss, leakage current and insulation resistance.

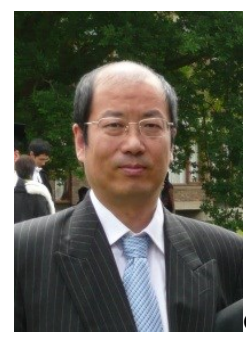
degrees in electrical engineering from Huazhong University of Science and
Technology, Wuhan, China, in 1983 and 1986, respectively, and the Ph.D. degree in electrical engineering from The University of Manchester, Manchester, U.K., in 1994. Now, He is a currently a Professor in the School of Engineering and Built Environment, Glasgow Caledonian University (GCU), Glasgow, U.K. Prof Zhou has over 30 years research experience in power systems and HV condition monitoring and has published over 40 papers in IET Journal and IEEE Transactions, among the 160 papers he has published in the area. Prof. Zhou is a Chartered Engineer, Fellow of IET and SMIEEE.

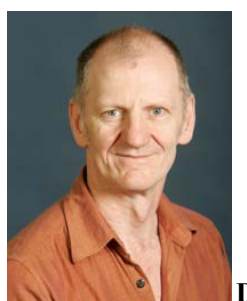

Donald M Hepburn (M'08) received his B.A. (Hons) from the Open University in 1987 and the Ph.D. degree from Glasgow Caledonian University (GCU) in 1994. He is a Senior Lecturer at GCU, a member of the IEEE, Institute of Physics, the IET and C.Eng. He has 20 years of industrial research experience and has been involved in research into HV insulation systems at GCU for over 20 years. His research interests cover monitoring physical and chemical change in HV/MV insulation materials and application of advanced digital signal processing to information from electrical, acoustic and RF monitoring techniques.

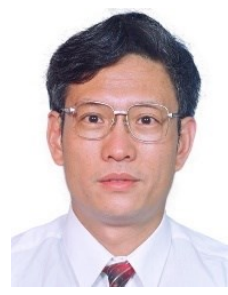

Wenjun Zhou (SM'13) was born in China on 1 July 1959. He received the Ph.D. degree in 1990 from Wuhan University of Hydraulic and Electrical Engineering. Currently, he is a professor at the School of Electrical Engineering of Wuhan University, China. He is a member of the High Voltage Committee of the Chinese Society of Electrical Engineering (CSEE), and the China Lightning Protection Standard Committee. His research interests include lightning protection and the diagnostic techniques for outdoor.

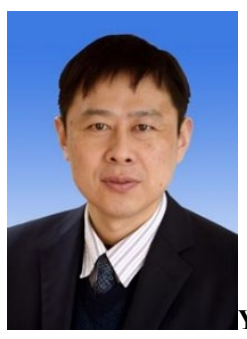
management.

Yuchuan Bao was born in China in 1970 . He received ments 